\title{
Intractable ulcerating enterocolitis of infancy
}

\author{
I R Sanderson, R A Risdon, J A Walker-Smith
}

\begin{abstract}
Five children (three boys, two girls) presenting in the first year of life with intractable diarrhoea had a number of features in common. All had ulcerating stomatitis, four had partial villous atrophy on small intestinal biopsy, all had colitis characterised by large ulcers with overhanging edges, and four had severe perianal disease; no stool pathogens were detected. Treatment with steroids, sulphasalazine, and azathioprine was unsuccessful. All five required subtotal colectomy. Four were children of consanguinous marriages, two were siblings of Pakistani origin, two were cousins of Arab origin, and the fifth was Portuguese. Although the diagnoses of Behçet's disease and Crohn's disease were considered, it appears that these children represent a distinct inherited condition affecting the whole gastrointestinal tract, particularly the colon.
\end{abstract}

Children who have chronic diarrhoea not due to an infectious agent in the first three months of life were described as having the syndrome of intractable diarrhoea of infancy. ${ }^{1}$ This syndrome is now defined as chronic diarrhoea in children who fail to thrive in their first year but who do not have a diagnosis that allows effective treatment. ${ }^{2}$ It comprises a heterogeneous group of conditions, some of which have now been characterised, ${ }^{34}$ but for which no cure has been found.

In many cases the cause of their clinical problem is a small intestinal enteropathy. At the Queen Elizabeth Hospital for Children, however, five such infants have presented with chronic inflammatory bowel disease, sited predominantly in the large intestine. These children also share other features and are likely to be examples of the same condition, which we have termed intractable ulcerating enterocolitis of infancy.

Two of the children have been previously reported as having an incomplete form of Behçet's disease. ${ }^{5}$ However, their subsequent course has not shown the development of the

Academic Department of Paediatric Gastroenterology, Queen Elizabeth Hospital for Children, Hackney Road, London E2 8PS I R Sanderson R A Risdon

J A Walker-Smith Correspondence to: Professor Walker-Smith. Accepted 17 September 1990

* Siblings from consanguinous marriages.

tCousins from consanguinous marriages. major criteria of this condition ${ }^{6}$ apart from aphthous stomatitis.

\section{Patients, methods, and results \\ PATIENTS}

The infants presented in the first two months of life (table 1), some with diarrhoea that later became bloody, and others with the passage of blood and mucus heralding the development of diarrhoea.

None of the children was of Anglo-Saxon origin. Cases 1, 2, 4, and 5 were the issue of marriages between cousins (table 1). Cases 1 and 2 were siblings and cases 4 and 5 were first cousins. Cases 4 and 5 each had two siblings who had died of intractable diarrhoea in infancy.

All five children failed to thrive, being below the third centile for weight by three months (table 2); three of the children later required parenteral nutrition.

The most striking physical signs were the development of ulceration in the mouth (fig 1) and perineal abnormalities consisting of fistulae and anal tags (fig 2). These features developed in infancy in all children except patient 3 (table 2), and occurred at around the same time as the change in bowel habit (table 1). The mouth ulcers were deep with sharply demarcated borders; they would remain for weeks before healing and then redeveloping elsewhere. The anal tags were multiple and fissures occurred spontaneously. Fistulae were seen opening onto the skin up to $3 \mathrm{~cm}$ from the anal margin. Genital ulcers were not observed.

Table 2 Clinical features of children with ulcerating enterocolitis of infancy: clinical signs

\begin{tabular}{lllc}
\hline $\begin{array}{l}\text { Case } \\
\text { No }\end{array}$ & $\begin{array}{l}\text { Weight centile } \\
\text { at } 3 \text { months }\end{array}$ & $\begin{array}{l}\text { Age of onset } \\
\text { of mouth ulcers }\end{array}$ & $\begin{array}{l}\text { Age of onset } \\
\text { of perineal } \\
\text { abnormalities }\end{array}$ \\
\hline 1 & $<3$ rd & 1 month & 5 months \\
2 & $<3$ rd & 1 week & 3 months \\
3 & $<3$ rd & 4 months & -3 months \\
4 & $<3$ rd & 5 weeks & 11 months \\
5 & $<3$ rd & 5 months & <
\end{tabular}

Table 1 Clinical features of children with ulcerating enterocolitis of infancy: symptoms and ethnic origin

\begin{tabular}{lllll}
\hline $\begin{array}{l}\text { Case } \\
\text { No }\end{array}$ & $\begin{array}{l}\text { Presenting change } \\
\text { in bowel habit }\end{array}$ & $\begin{array}{l}\text { Age of change } \\
\text { in bowel habit }\end{array}$ & Ethnic origin & Place of birth \\
\hline $1^{*}$ & Loose stools & 5 weeks & Pakistani & England \\
$2^{*}$ & Loose stools & 8 weeks & Pakistani & England \\
3 & Blood and mucus in stools & 8 days & Portuguese & Portugal \\
$4 \dagger$ & Blood and mucus in stools & 6 weeks & Arabic & Arabian Gulf \\
$5 \dagger$ & Loose stools & 6 days & Arabic & Arabian Gulf \\
\hline
\end{tabular}




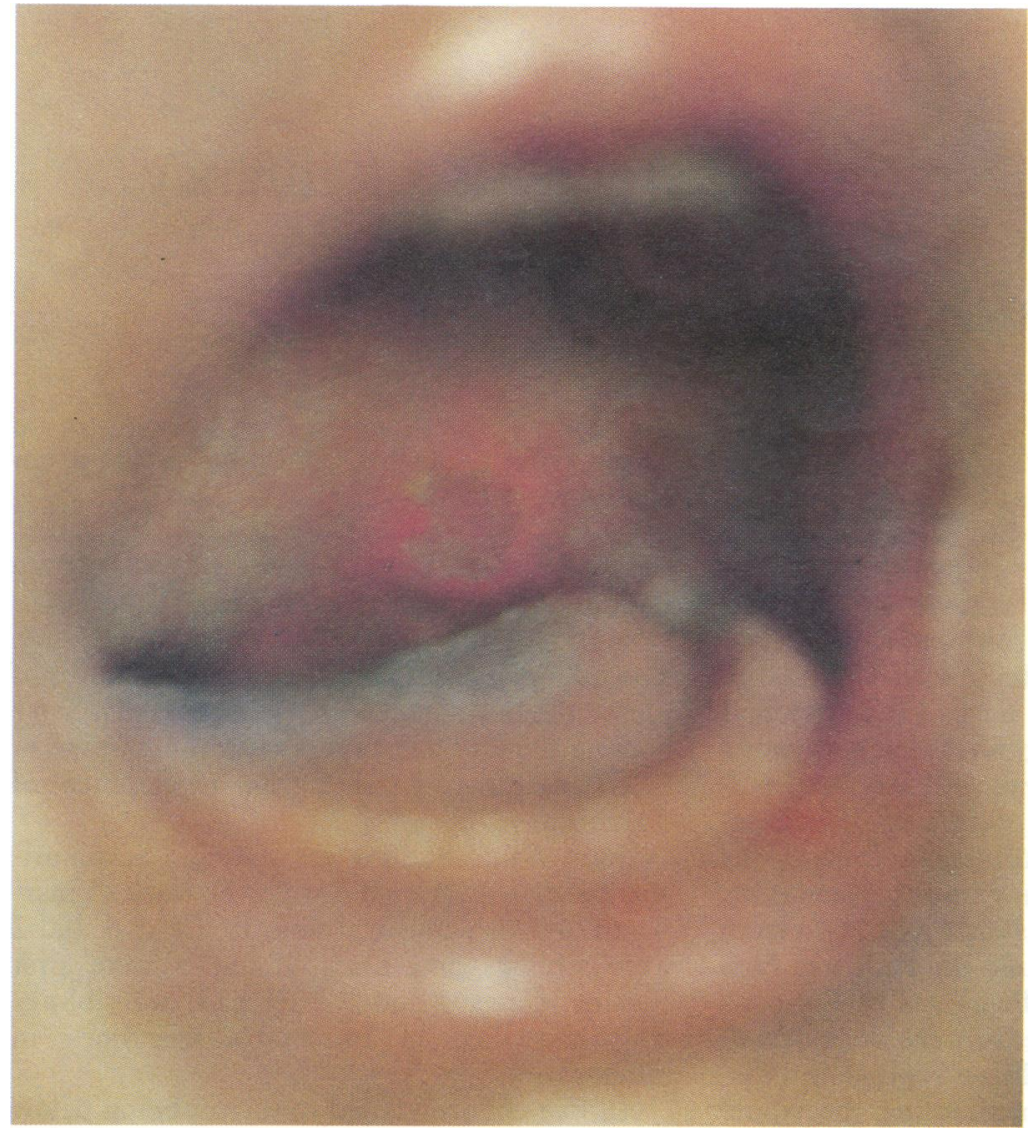

Figure 1 Oral cavity of case 4 showing large ulcer at the back of the mouth.

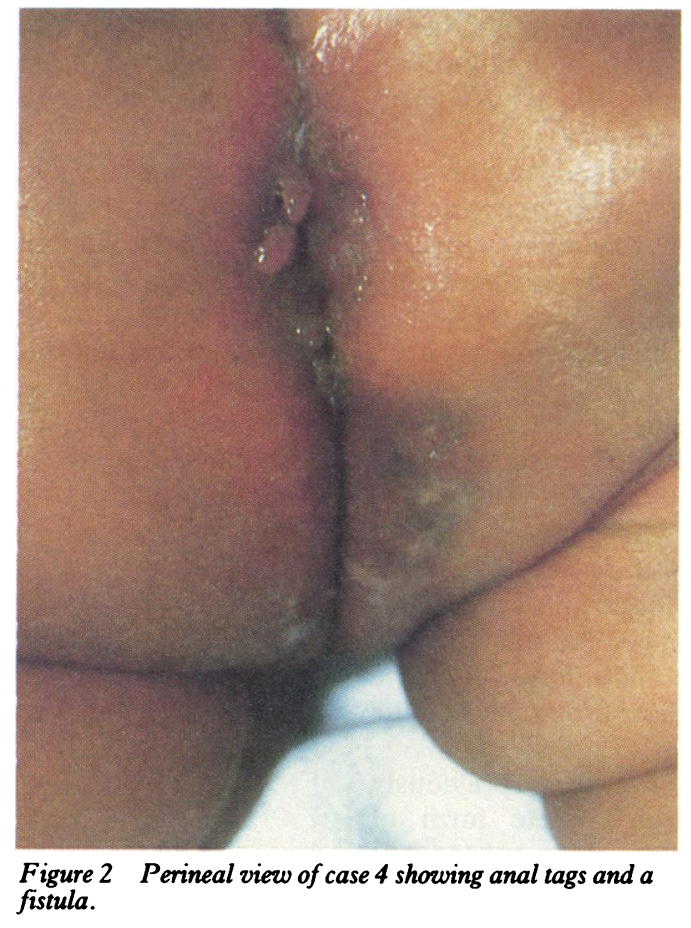

No abnormalities were seen outside the gastrointestinal tract. In particular, no evidence of joint abnormalities, skin lesions, or ocular inflammation was found.

\section{LABORATORY INVESTIGATIONS}

Intensive investigations were made into the cause of the diarrhoea. No stool pathogens were isolated and gut autoantibodies were not present; autoantibodies to DNA, smooth muscle, gastric parietal cells, and thyroid were also negative. At first erythrocyte sedimentation rates and $C$ reactive protein concentrations were normal, but as the illness progressed and the diarrhoea worsened with increasing amounts of blood and mucus associated with febrile episodes, these indices of inflammation became abnormal.

One notable abnormality (fig 3) was an increased concentration of circulating immunoglobulins. IgA was appreciably raised in each case and in all but one case IgM was also raised; in two children IgG was raised.

\section{INVESTIGATIONS OF THE GASTROINTESTINAL}

\section{TRACT}

Small intestinal biopsies were performed at the time of referral and at subsequent intervals (fig 4). Figure 4 also charts the timing of corticosteroid treatment and colectomy (see below). All children except case 4 had an abnormal proximal small intestinal biopsy at some point. The abnormalities were patchy (fig 5) and consisted of shortening of villi and in some cases lengthening of crypts; the villous crypt ratios varied from $3: 1$ to $1: 1$. Intraepithelial lymphocyte populations were not increased but there was a mild increase in the numbers of lymphocytes and plasma cells of the lamina propria in some instances.

The most striking abnormalities were found in the colon. Endoscopy revealed in every child an inflamed large intestine with deep ulcers many of which were greater than $1 \mathrm{~cm}$ in diameter. The ulcers were seen throughout the colon and their density was such that no view of the colon was free of them.

The ulcers were flask shaped with overhanging edges (fig 6) and extended into the submucosa. The base of the ulcer contained necrotic debris and beneath there was granulation tissue. Acute and chronic inflammatory cells were seen in large numbers (fig 7) around the ulcers and in lesser numbers between the ulcers. No area of the colon was histologically normal. Extensive

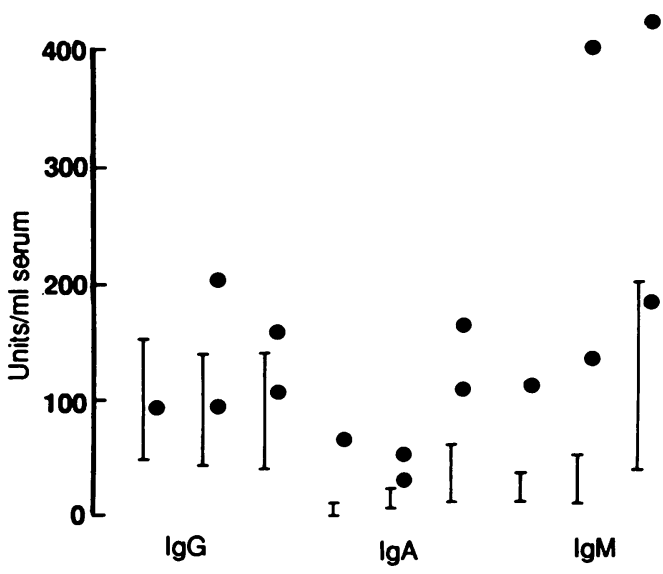

Figure 3 Circulating immunoglobulin concentrations. The normal ranges $(S D)$ are shown for each sample; ranges vary according to the age of the child at which the sample was taken. Conversion factors from units/ml to g/l: IgG $\times 0.087$, $I g A \times 0.016$, and $I g M \times 0.0086$. 

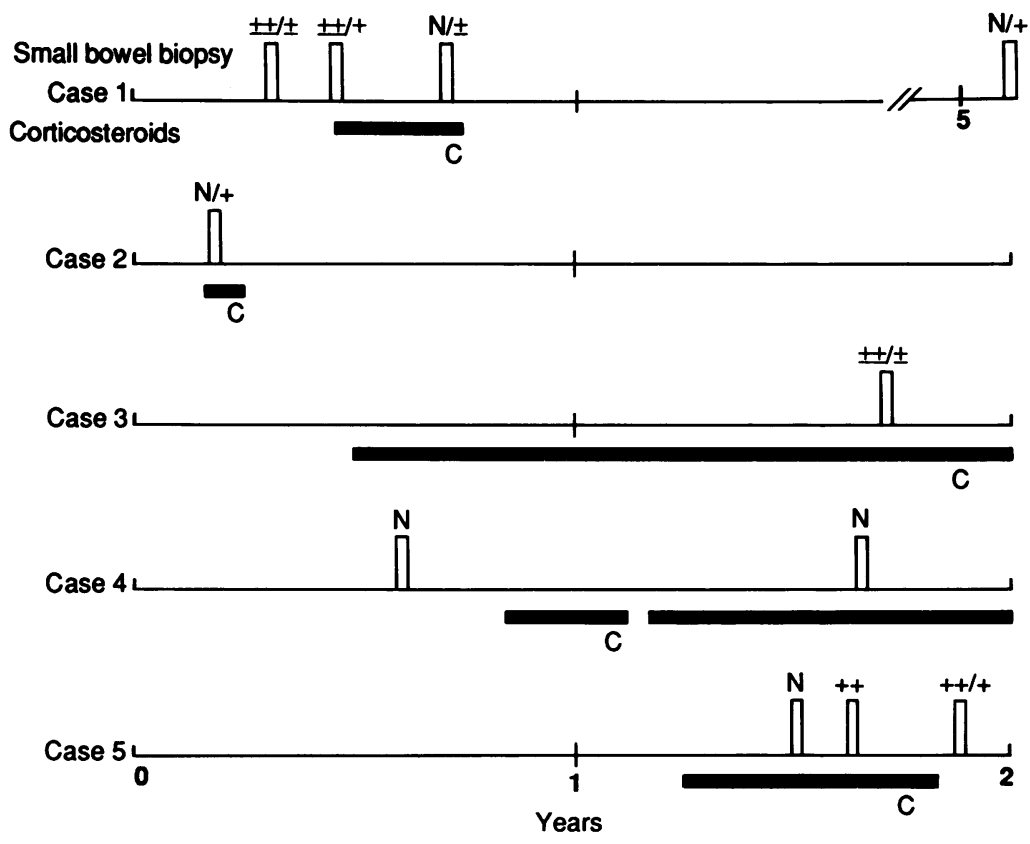

Figure 4 Small bowel biopsy appearances in five children with intractable ulcerating enterocolitis of infancy. $++=$ Villous height $<100 \mu \mathrm{m} ;+=$ villous height $100-200 \mu \mathrm{m}$; $N=$ normal small intestinal mucosa; underlining $=$ crypt depth $>200 \mu m ;$ and $/=$ patchy abnormality. The duration of prednisolone and the timing of colectomy $(C)$ are also shown.

examination of resected specimens showed no evidence of vasculitis. In particular there was no evidence of pericapillary or perivascular localisation of monocytes; the intima was not affected and no fibrinoid necrosis was found. Granulomas were not found in the resected specimens.

In summary, abnormalities were found throughout the gastrointestinal tract (table 3). Oesophagoscopy and gastroscopy were not routinely performed in these children. It was undertaken, however, in case three who showed evidence of oesophageal ulceration, but no abnormality in the stomach or upper duodenum.

\section{MANAGEMENT}

All children had been given a diet free of cows' milk before referral. This management had not led to an alleviation of symptoms; however, cows' milk elimination was continued after referral. It was reintroduced back into the diet at the age of 2 years in cases 1 and 2 .

In view of the features of chronic inflammatory bowel disease, corticosteroids were introduced (fig 4); however this treatment produced no amelioration of symptoms. Azathioprine (2 $\mathrm{mg} / \mathrm{kg} /$ day) was added but despite this the children continued to have bloody diarrhoea and fevers. An eight week course of cyclosporin was given to cases 4 and 5 without improvement. An initial dose of $5 \mathrm{mg} / \mathrm{kg} /$ day was increased threefold over three weeks in order to achieve circulating concentrations of $150 \mu \mathrm{g} / \mathrm{l}$. In every case the colitis became so severe that subtotal colectomy was needed to arrest deterioration.

\section{LONG TERM SEQUELAE}

After subtotal colectomy, there was a considerable improvement in the children's condition. Fevers subsided and bloody diarrhoea ceased. Ileostomy output was of good consistency despite, in most cases, evidence of a patchy

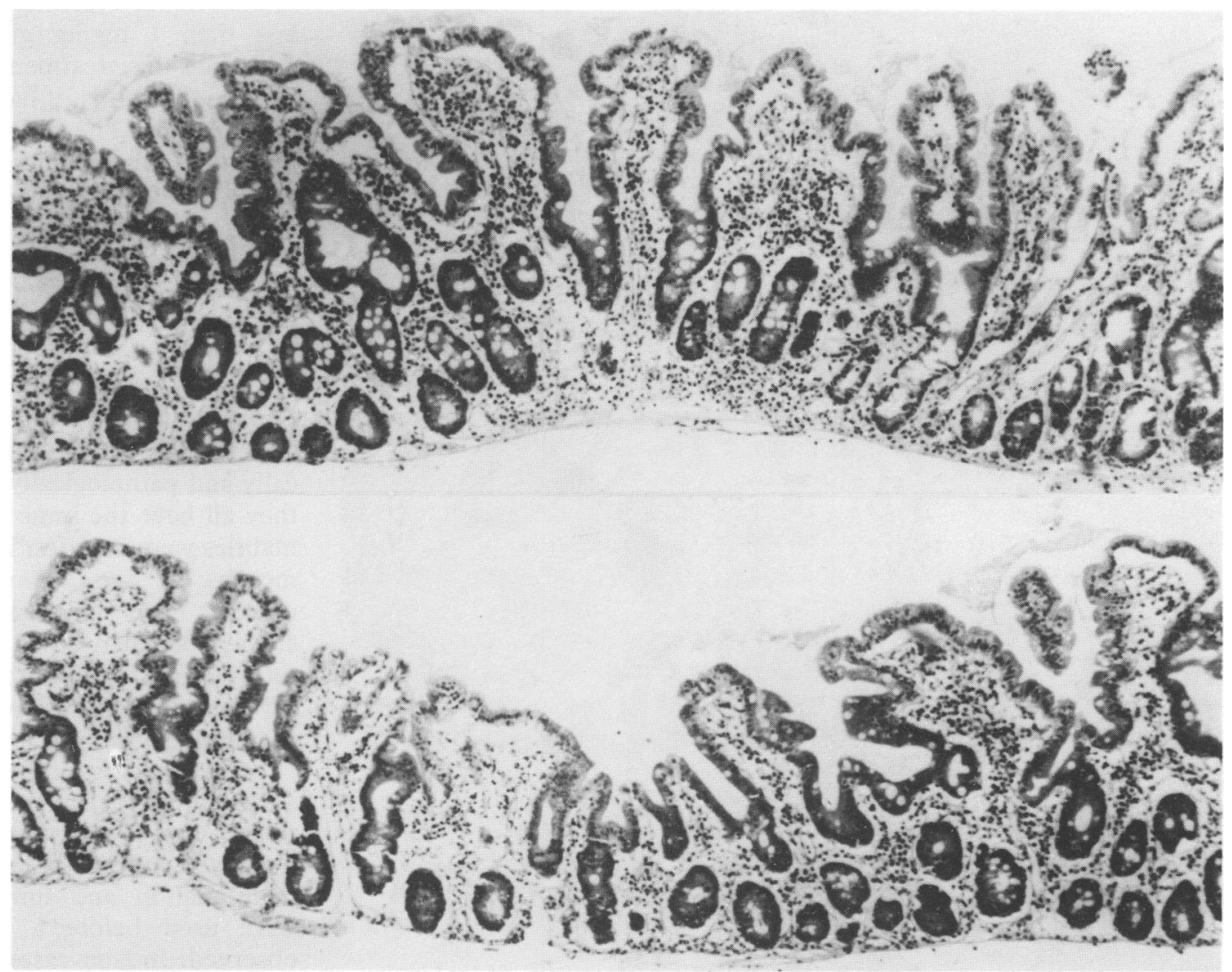

Figure 5 Histology of two sections of small intestine from a single biopsy demonstrating the patchy nature of the villous atrophy. 


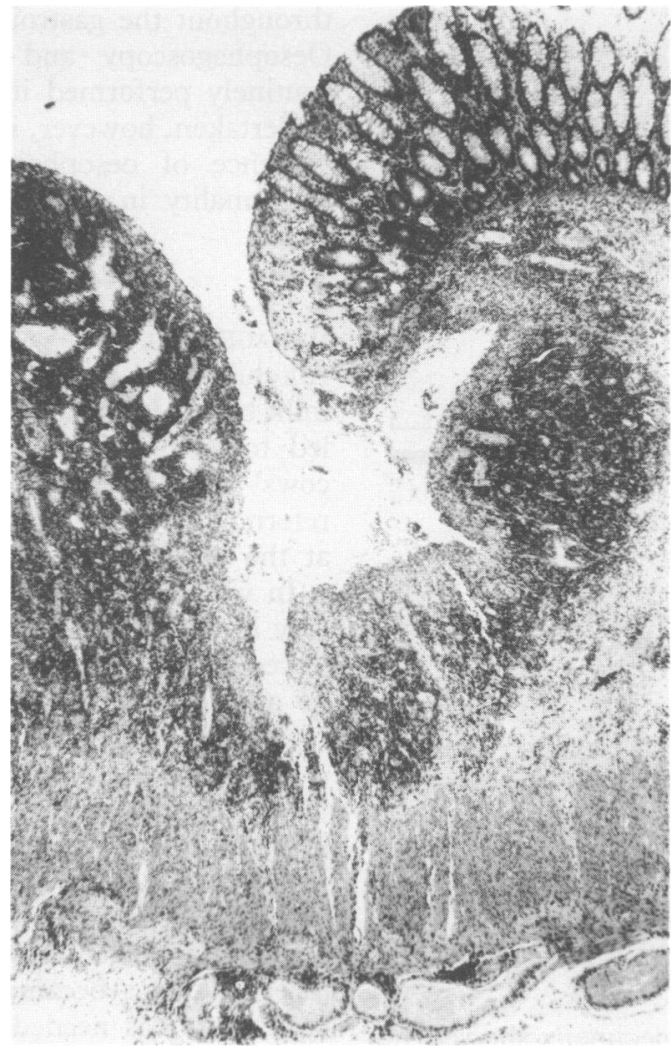

Figure 6 Histology of resected specimen of large bowel mucosa $(\times 50)$ demonstrating the large flask shaped ulcer with underlying edges.

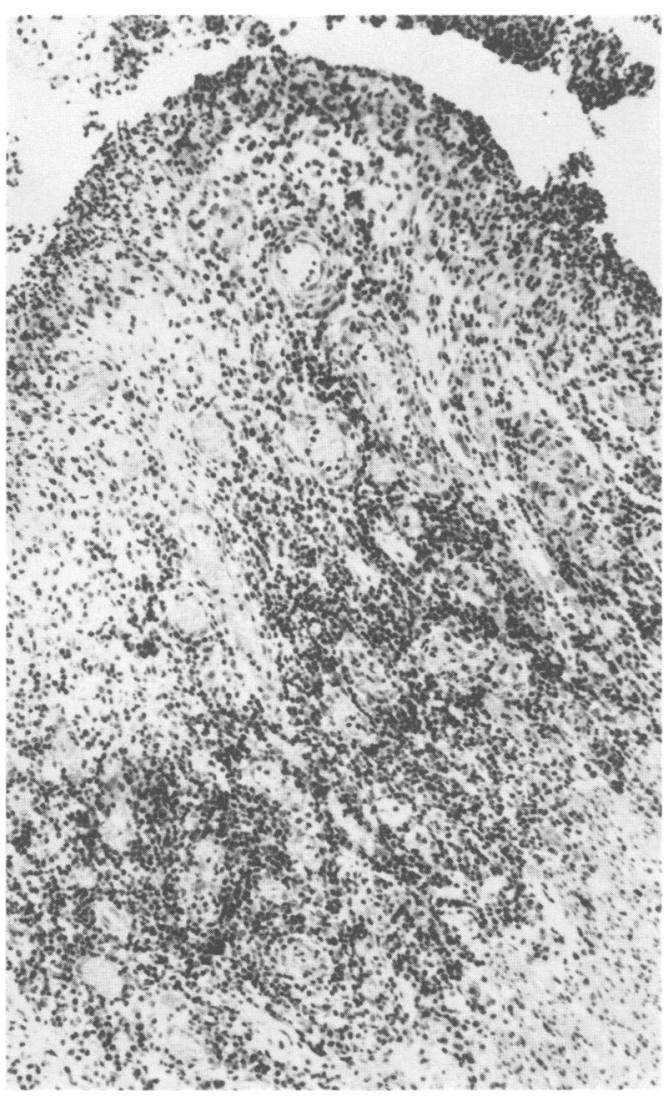

Figure 7 Histology of resected specimen of large bowel mucosa $(\times 190)$ showing increased numbers of acute and chronic inflammatory cells.
Table 3 Sites of the gastrointestinal tract where inflammation was found (indicated by plus signs)

\begin{tabular}{lllll}
\hline $\begin{array}{l}\text { Case } \\
\text { No }\end{array}$ & $\begin{array}{l}\text { Mouth } \\
\text { ulcers }\end{array}$ & $\begin{array}{l}\text { Small bowel } \\
\text { enteropathy }\end{array}$ & Colitis & $\begin{array}{l}\text { Perineal } \\
\text { disease }\end{array}$ \\
\hline 1 & + & + & + & + \\
2 & + & + & + & + \\
3 & + & + & + & - \\
4 & + & - & + & + \\
5 & + & + & + & + \\
\hline
\end{tabular}

Table 4 Long term sequelae in patients with ulcerating enterocolitis of infancy

\begin{tabular}{lll}
\hline $\begin{array}{l}\text { Case } \\
\text { No }\end{array}$ & $\begin{array}{l}\text { Time since } \\
\text { colectomy } \\
\text { (years) }\end{array}$ & Further problems \\
\hline 1 & 8 & $\begin{array}{l}\text { Anal abscess after ileorectal reanastomosis } \\
\text { requiring further ileostomy }\end{array}$ \\
2 & 6 & $\begin{array}{l}\text { Fistulae around ileostomy, recurrent } \\
\text { mouth ulcers } \\
\text { Ileorectal reanastomosis, recurrent ileal } \\
\text { and rectal ulcers, mouth ulcers }\end{array}$ \\
3 & 6 & $\begin{array}{l}\text { Recurrent mouth ulcers } \\
\text { Ileocutaneous and jejunocutaneous } \\
\text { fistulae, died after extensive small bowel } \\
\text { resection }\end{array}$ \\
\hline
\end{tabular}

enteropathy. All children were well enough for discharge from hospital. Since then evidence of gastrointestinal inflammation has been observed in all (table 4). In one child (case 5) the inflammation extended within the small intestine to an extent where massive small bowel resection was indicated. The child later died postoperatively. In the others the inflammation, which can be particularly severe in the mouth and around the anus, has not prevented these children from living at home and leading normal life styles but has necessitated two (cases 3 and 4) to remain on low doses of systemic corticosteroids-that is less than $1 \mathrm{mg} / \mathrm{kg}$ given on alternate days. Although this treatment was ineffective in controlling the colitis, it has reduced the severity of these ulcers. The oral ulceration has affected feeding. Cases 3 and $\mathbf{4}$ are gaining weight below, albeit parallel to, the third centile, but their linear growth is now between the 25th and 50th centile. Cases 1 and 2 are thriving. Ocular inflammation or genital ulcers have never been observed.

\section{Discussion}

The similarities between these cases both clinically and pathologically make it very likely that they all have the same condition. Their abnormalities were manifest in early infancy and by 3 months of age the children were severely unwell. Each had lesions in the mouth and colon; four had small intestinal disease, and four perineal disease (table 3 ). None responded to immunosuppressive treatment and all required colectomy.

In the index case (case 1) the changes in the small bowel were at first thought to be a reflection of cows' milk sensitive enteropathy; but improvement was slow in response to dietary manipulation and immunosuppressive agents were used before a significant change was observed. In later cases, the enteropathies were discovered after some months of cows' milk elimination. It is probable, therefore, that the 
small bowel changes are part of the chronic inflammatory disease.

Alterations in the severity of patchy enteropathies are difficult to assess on repeated biopsy specimens because of sampling variation. It is possible that all children had a patchy enteropathy at the time of each biopsy, but that on some occasions only normal tissue was sampled (fig 3).

There can be no doubt that these children represent a form of chronic inflammatory bowel disease; two conditions that have some similarities are Crohn's disease and Behçet's disease.

Crohn's disease very rarely occurs in infancy. Those cases that have been reported display mainly small bowel disease with only occasional colonic involvement. ${ }^{7}$ Some authors have cast doubts as to whether these infants did indeed have the same condition as exists in older children and adults. ${ }^{8}$ The pathological features of the colon of the five cases presented here, who had large flask shaped ulcers and no characteristic aphthous ulcers, are not the features of Crohn's colitis and histology of the resected colons showed no granulomas.

When the colon is involved in Behçet's disease, its features share a number of similarities with our five cases. ${ }^{910}$ Flask shaped ulcers are a particular feature. The overhanging mucosa is caused by loss of connective tissue in the submucosa. These features have been reported in children as well as adults. ${ }^{11}$ However, a vasculitis is the hallmark of Behçet's disease both systemically ${ }^{12}$ and within the gastrointestinal tract. ${ }^{13}$ In some well documented cases of Behçet's colitis a vasculitis has not been evident when only biopsy specimens have been examined. ${ }^{14}$ Colectomy specimens were studied in these five children, however, and no evidence of pericapillary and perivascular localisation of monocytes was seen; the intima was not affected and no fibrinoid necrosis was found. This, therefore, casts doubt on the diagnosis of Behçet's colitis.

A diagnosis of Behçet's colitis would be more secure if the bowel inflammation were found in children who otherwise fulfilled the criteria for Behçet's disease. The diagnosis depends on the Hippocratic method of grouping features together in a symptom complex that makes it necessary to adopt diagnostic criteria. ${ }^{6}$ Four major criteria are now established: genital ulceration, aphthous stomatitis, ocular inflammation, and skin lesions. When only two of these criteria are present a diagnosis of incomplete Behçet's disease is made. ${ }^{14}$ The five reported cases have displayed only one major criterion-aphthous ulceration. In children it is possible for a second major criterion to develop months or even years after the first criterion, ${ }^{11}$ and it was thought on first reporting the index case that new extraintestinal features may later present. ${ }^{5}$ However, it is now 10 years since the mouth ulceration was noted and no abnormalities associated with Behçet's disease have been observed outside the gastrointestinal tract. As the years pass, the likelihood of developing a second major diagnostic criterion becomes more remote. Recently, Stringer et al have warned against making a diagnosis of Behçet's colitis when there are no features of the disease outside the gastrointestinal tract. ${ }^{15}$ We therefore feel it unwise to label these infants as having Behçet's colitis and have described them as having intractable ulcerating enterocolitis of infancy.

A notable feature of the children is the family associations. Four of the five children are the issue of consanguinous marriages. Moreover, cases 1 and 2 are siblings and cases 4 and 5, cousins. The two pairs of siblings of cases 4 and 5 died of intractable diarrhoea of infancy and it is possible that they had a similar condition. A genetic basis for the disease is likely, possibly inherited as an autosomal recessive gene. Two familial causes of intractable diarrhoea of infancy have been described; familial enteropathy, ${ }^{16}$ which is now thought to be the same as congenital microvillous atrophy, ${ }^{3}$ is a defect of the enterocyte cytoskeleton and not a form of chronic inflammatory bowel disease. Secretory diarrhoea with enterocolitis cystica superficialis has characteristic dilatations of the crypts not seen in the present cases. ${ }^{17}$

The aetiology of intractable ulcerating enterocolitis of infancy is uncertain. All children were normal at birth and had no diarrhoea on the first day of life. It is tempting to speculate that the defects found in these children represent an inherited inability to deal immunologically with normal bacterial colonisation of the gastrointestinal tract. The presence of the most severe disease in those areas that are normally most heavily colonised supports this hypothesis.

1 Avery GB, Villavicencio O, Randolph J. Intractable diarrhoea of infancy. Pediatrics 1968;41:712-22.

2 Phillips AD, Walker-Smith JA. Role of small intestinal biopsy in infantile intractable diarrhoea. Gastroenterology 1986;91:791-2.

3 Phillips AD, Jenkins P, Raafat F, Walker-Smith JA. Congenital microvillous atrophy: specific diagnostic features. Arch Dis Child 1985;60:730-5.

4 Mirakian R, Richardson A, Milla PJ, et al. Protracted diarrhoea of infancy: evidence in support of an autoimmune variant. $B M Y$ 1986;293:1132-6.

5 Chong SKF, Wright VM, Nishigame T, et al. Infantile colitis: a manifestation of intestinal Behcet's syndrome. colitis: a manifestation of intestinal Behçet'

6 Mason RM, Barnes CG. Behçet's syndrome with arthritis. Ann Rheum Dis 1969;28:95-103.

7 Miller RC, Larsen E. Regional enteritis in early infancy. Am f Dis Child 1971;122:301-11.

8 Gryboski J, Walker WA. Regional enteritis (Crohn's disease) Gastrointestinal problems in the infant. 2nd Ed. Philadelphia: WB Saunders, 1983:460-3

9 Smith GE, Kine LR, Pitcher JL. The colitis of Behçet's disease: a separate entity? Colonoscopic findings and literature review. American fournal of Digestive Diseases 1973;18: 987-1000.

10 Kasahara Y, Taraka S, Nishino M, Umemura $H$, Shiraha $S$, Kanyama $T$. Intestinal involvement in Behçet's disease: a review of 136 surgical cases in the Japanese literature. $D$ is Colon Rectum 1981;24:103-6.

11 Mundy TM, Millar JJ. Behçet's disease presenting as chronic aphthous stomatitis in a child. Pediatrics 1978;62.205-8.

aphthous stomatitis in a child. Pediairics 1978,62:205-8. of 10 cases, 3 with new manifestations. Ann Intern Med of 10 cases, 3 with

13 Baba S, Manutu $\dot{M}$, Ando K, Teramoto T, Endo I. Intestinal Behçet's disease: report of five cases. Dis Colon Rectum 1976;19:428-40.

14 Curth HO. Recurrent genito-oral apthosis and uvietis with hypopyon (Behçet's syndrome) Archives of Dermatology and Syphilis (Chicago) 1946;54:179-96.

15 Stringer DA, Cleghorn GJ, Durie PR, Daneman A, Hamilton JR. Behçet's syndrome involving the gastrointestinal tract-a dianostic dilemma in childhood. Pediatr Radiol 1986;16:131-4.

16 Davidson GP, Cutz E, Hamilton JR, et al. Familial enteropathy; a new syndrome of protracted diarrhoea from birth failure to thrive and hypoplastic villus atrophy. Gastroenterology 1978;75:783-90.

17 Pelletier VA, Galiano N, Brochu P, Morin CL, Weber AM Roy CC. Secretory diarrhea with protein losing enteropathy, enterocolitis cystica superficialis, intestinal lymphangiectasia and congenital hepatic fibrosis: a new syndrome. I Pediatr 1986;107:61-5. 